\title{
Uninvestigated dyspepsia and associated factors of patients with gastrointestinal disorders in Dessie Referral Hospital, Northeast Ethiopia
}

\author{
Abdurahaman Seid ${ }^{1 *}$, Zemenu Tamir ${ }^{2}$ and Wondmagegn Demsiss ${ }^{3}$
}

\begin{abstract}
Background: Dyspepsia is a common problem in the community and clinical practice with symptom(s) considered arising from the gastroduodenal region. Dyspepsia burden and associated factors vary from country to country. The aim of this study was to determine the prevalence of uninvestigated dyspepsia (UD) using Rome III criteria, associated risk factors and self-reported dyspepsia symptoms' correlation with $\mathrm{H}$. pylori infection.

Methods: A cross-sectional study was conducted among randomly selected 318 out patients with gastrointestinal complaints during the period from September 1 to December 30, 2015. All patients completed a questionnaire for collecting data regarding sociodemographic, lifestyle and functional gastrointestinal disorders. Diagnosis of dyspepsia was made according to the Rome III criteria. H. pylori infection was assessed using stool antigen test. SPSS version 20.0 statistical software package was used for data analysis.

Results: From a total of 318 patients, 48.4\% had UD according to Rome III criteria; with $42.1 \%$ symptoms of epigastric pain/burning, $26.1 \%$ postprandial fullness and $22.6 \%$ early satiation. Epigastric pain/burning (AOR $=1.92$, $95 \% \mathrm{Cl} 1.07-3.43)$, early satiation ( $\mathrm{AOR}=2.68,95 \% \mathrm{Cl} 1.38-5.20)$ and belching ( $\mathrm{AOR}=4.7,95 \% \mathrm{Cl} 1.54-14.40)$ were significantly correlated with $\mathrm{H}$. pylori infection. H. pylori infection ( $\mathrm{AOR}=4.33,95 \% \mathrm{Cl} 2.41-7.76$ ) and aspirin/NSAIDs consumption $(A O R=5.29,95 \% \mathrm{Cl} 2.82-9.93)$ were independent risk factors for UD. However, consumption of raw fruits/ vegetables at least once a week ( $A O R=0.48,95 \% \mathrm{Cl} 0.24-0.98)$ and taking two or more cups of tea a day $(A O R=0.339,95 \% \mathrm{Cl} 0.17-0.70)$ were inversely associated with UD.
\end{abstract}

Conclusions: UD is highly prevalent among adults with gastrointestinal complaints. H. pylori infection is significantly associated with UD and correlates with its symptoms. Individuals with epigastric pain/burning, early satiation and belching should be primary focus of $H$. pylori infection diagnosis and treatment. The role of consumption of tea, raw fruits and vegetables on dyspepsia needs further large scale study.

Keywords: H. pylori, Uninvestigated dyspepsia, Rome III, Self-reported, Ethiopia

\footnotetext{
* Correspondence: nebat_abdurae2003@yahoo.com; gechdk2000@yahoo.com

'Department of Medical Laboratory Sciences, College of Medicine and

Health Sciences, Wollo University, Po. Box 1145, Dessie, Ethiopia

Full list of author information is available at the end of the article
}

(c) The Author(s). 2018 Open Access This article is distributed under the terms of the Creative Commons Attribution 4.0 International License (http://creativecommons.org/licenses/by/4.0/), which permits unrestricted use, distribution, and reproduction in any medium, provided you give appropriate credit to the original author(s) and the source, provide a link to the Creative Commons license, and indicate if changes were made. The Creative Commons Public Domain Dedication waiver (http://creativecommons.org/publicdomain/zero/1.0/) applies to the data made available in this article, unless otherwise stated. 


\section{Background}

Functional gastrointestinal disorders (FGIDs) are highly prevalent in the general population and are frequent cause for consultation of a general practitioner [1]. Individuals with FGIDs contribute heavily to healthcare utilization [2]. The Rome III criteria for diagnosis of FGIDs were developed in 2006 [3], and since then a few studies have estimated prevalence of FGIDs, described associated factors, signs and symptoms using this criteria [4].

Dyspepsia is one of a common symptom complex of FGIDs with an extensive differential diagnosis and a heterogeneous pathophysiology. According to Rome III definition, dyspepsia is "chronic or recurrent pain and/or discomfort thought to originate from the gastroduodenal region" and at least having one or more of the following symptoms: postprandial fullness (PPF), early satiation (ES), epigastric pain or burning [5-7]. Moreover, one symptom must be present for at least the last 3 months with an onset of symptoms at least 6 months prior to diagnosis [7].

Patients with symptoms of dyspepsia but didn't undergo any investigations such as upper gastrointestinal (GI) endoscopy and is not categorized as functional or organic in etiology are classified as having uninvestigated dyspepsia (UD), whereas those who undergo investigation and have no detectable cause for their symptoms are considered to have functional dyspepsia (FD) [6]. Numerous cross-sectional surveys reported different prevalence of dyspepsia in the community which varies from $7 \%$ to $54.6 \%$, and globally estimated that $25 \%$ of the general populations suffer from dyspeptic symptoms [8-12]. High prevalence of UD (41.2\%) was observed in the general population with $70-80 \%$ of patients with dyspepsia had no clinically significant findings at endoscopy [12]. Recently conducted systematic review and meta-analysis has demonstrated $21 \%$ pooled prevalence of UD, but varied among countries $(1.8 \%$ to $57.0 \%)$ and according to the criteria used to define its presence [13].

Dyspepsia complaints are the most common reasons for outpatient visits to primary care providers [5, 14] and $20 \%$ to $40 \%$ gastroenterology appointments [14]. Both in an uninvestigated dyspeptic and FD patients, the most prevalent symptoms are PPF (68-86\%), upper abdominal bloating (68-84\%), epigastric pain (68-74\%), ES $(49-72 \%)[15,16]$, belching $(50-60 \%)$, epigastric burning $(35-57 \%)$, nausea $(39-65 \%)$ and vomiting $(23-31 \%)$ [16].

The causes of dyspepsia remain uncertain as being females and underlying psychological disturbances contribute to FD, whilst environmental/lifestyle factors such as poor socio-economic status, smoking, increased caffeine intake and ingestion of non-steroidal antiinflammatory drugs (NSAIDs) appear to be more related to UD [17]. Moreover, the role of $H$.pylori infection in dyspepsia is still unclear. Some authors indicated no association between $H$. pylori infection and dyspepsia [18-21], whereas others indicated that dyspepsia may be a sign of acute or chronic $H$. pylori infection as evidenced from population-based study conducted in UK [22].

In Ethiopia, many hospital-based studies reported different prevalence rates of $H$. pylori infection among dyspeptic patients [21, 23-26], but have not estimated the burden of dyspepsia. Moreover, Rome III criteria have not been widely applied for diagnosis and classification of FGIDs. Thus, the proportion of dyspeptic patients and their frequent typical symptoms of individuals presented with FGIDs were not documented according to Rome III criteria. Furthermore, no study has been conducted concerning potential risk factors of dyspepsia.

The determination of dyspepsia burden along with its associated symptoms and potential risk factors is important to increase physicians' ability of symptoms-based approach of sufferers to provide more precise diagnosis, treatment and prevention of the disorder particularly in resource limited settings like Ethiopia. Therefore, the aim of this study is to assess the prevalence of UD using Rome III criteria and its major symptom types of adults with FGIDs complaining patients. Furthermore, the present study is designed to assess associated risk factors of UD and correlation of $H$. pylori infection with selfreported functional upper GI symptoms.

\section{Methods}

\section{Study patients and setting}

This cross-sectional study was conducted at Dessie Referral Hospital, Dessie town, Northeast Ethiopia, from September 1 to December 30, 2015. The sample size was estimated to be 384 by taking $50 \%$ prevalence since there was no previous similar study in Ethiopia. The study population consisted of randomly selected new adult patients fulfilling the inclusion criteria at the outpatient department of the hospital.

We assessed the number of GI symptomatic patients who visited the hospital of previous comparative months of the study period. An average of 15 new GI symptomatic patients attended the outpatient department each day. In our country, working day of the month are Monday to Friday ( 5 days) giving a total of 22 days per month. The total expected new symptomatic patients attending the hospital during the study period were estimated to be 1320. The average number of study participants included per day, obtained by dividing the sample size to total working day of study period, was approximately 5 . When the total population was divided by the sample size, the sample interval was found 3 . The first person was selected by lottery method and then systematic random sampling method was used for selecting the patients at an interval of every 3 patients using the sequential order of their card number as a sampling frame. 


\section{Inclusion criteria}

The presence of at least one of the following GI complaints existing for at least 3 months with the onset of symptom at least 6 months before clinical visit. These includes abdominal pain, bloating, nausea, vomiting, ES, PPF, heartburn, regurgitation, epigastric pain/burning and belching.

\section{Exclusion criteria}

GI symptomatic patients less than 18 years of age, and who took treatment against $H$. pylori infection within 3 months prior to this study, those who used proton pump inhibitors or $\mathrm{H} 2$-blockers for more than two weeks before study enrollment, presence of confirmed systemic disease such as congestive heart failure, coronary heart disease, liver failure, diabetes mellitus, thyroid disease, hematological diseases (for all case it is obtained by reviewing their medical documents), presence of major psychiatric disorders and pregnant mothers were excluded. Patients who were unable to communicate, and at emergency were also excluded.

\section{Questionnaires}

Study participants were asked to complete the dyspepsia questionnaire consisting FD modules of FGIDs and scored using Rome III algorithm [27]. Sociodemographic data (age, gender, schooling level, residence, occupational and marital status) and life style (consumption of tea, coffee, spice food, raw fruits and vegetables, alcohol, and NSAIDs) related factors were also collected. We adapted a previously validated FD module of FGIDs questionnaire (English version) [27] and translated in to the local language, "Amharic" version, through a process of translation and back translation before data collection. "Amharic" is mother tongue of population in the study area.

The translation process was as follows: Two medical professional who were native speakers of" Amharic" and fluent in English, undertook translations independently. One professional translated the English version to "Amharic" and the other translated the "Amharic" version back to English. The original and back-translated (English) versions were compared to detect any misunderstandings, mistranslations, or inaccuracies in the "Amharic" draft questionnaire. Feed backs about the "Amharic" version of the FD module of FGIDs questionnaire was obtained from experts in gastroenterology. The translated questionnaire was administered to 19 participants with FGIDs to assess the clarity, understandability, and appropriateness of the translation's wording so that the final version which contains 30 questions was used to collect required information. Similar procedure was followed for preparing "Amharic" version of the socio-demographic and life style related questionnaire. For participants who can't read and write, interview was employed. The clinical residents explained the question and queries regarding the meaning of medical terms and elaboration of symptoms when asked by the patients.

Dyspepsia was assessed according to the Rome III criteria as having one or more of the following: PPF, ES, epigastric pain, and/or epigastric burning for the past three months with onset at least six months before diagnosis [3]. However, UD was not directly addressed by the Rome III criteria. We depended on the symptoms that were defined for FD by the Rome III criteria in order to recognize those with dyspepsia and since no upper GI endoscopy was performed, patients who fulfill the symptomatic criteria were diagnosed as UD. Therefore, individuals were classified as having UD if they have reported experiencing at least one of the following symptoms: (1) bothersome postprandial fullness happening after ordinary sized meals; (2) early satiation that prevents finishing a regular meal; (3) epigastric pain/ burning localized to the epigastrium.

\section{Evaluation of $H$. pylori status and ABO blood group}

About $20 \mathrm{~g}$ of fresh stool was collected from each participant in sterile and screw caped containers. The presence of $H$. pylori antigen was determined using monoclonal anti-H.pylori antibody conjugated with colloid gold nitrocellulose membrane strip (Rapid stool antigen test) based on a lateral flow chromatographic immunoassay technique. Specimens were tested using one step stool antigen test (Zhejiang Orient Gene Biotech CO., LTD, China) with $94.9 \%-100 \%$ sensitivity and 95-100\% specificity [28]. Test results were read and interpreted according to the manufacturer's instructions. This test kit is validated and approved by the ministry of health of the country and currently employed for the diagnosis of H.pylori infection in the country. Five ml of venous blood was collected and $\mathrm{ABO}$ blood grouping was performed by slide agglutination test using monoclonal anti-A, anti-B, anti-AB and anti-D (Rho) antibodies.

\section{Statistical analysis}

All completed questionnaires were coded. Data analysis was performed using SPSS version 20 in four major steps. First, descriptive statistics were used to summarize the participant characteristics. The chi square $\left(\chi^{2}\right)$ test was used to test the association between sociodemographic and lifestyle factors and dyspepsia. Possible risk factors for dyspepsia were initially examined using univariate analyses. Risk factors with $p<0.25$ were entered to logistic regression model using stepwise backward logistic regression analysis to identify the risk factors independently associated with dyspepsia. All tests 
were two-tailed and the level of statistical significance was set at $p<0.05$ along with the corresponding odds ratio (OR) and 95\% confidence intervals (CI) in cases of significant associations.

\section{Ethical consideration}

The study was commenced after ethically approved by the research ethics committee of Wollo University. Permission to conduct the study was also obtained from the hospital administration. Written informed consent was obtained from each study participant and the results were kept confidential. Any result that was necessary for the patient was communicated with the physician for appropriate management.

\section{Results}

\section{Sociodemographic and life style characteristics}

Among 383 randomly selected participants with GI complaints, 24 were not eligible (10 were below 18 years old, 14 were with symptom onset less than 6 months), and 41 returned incomplete questionnaire. Therefore, a total of 318 participants with complete information were included in the final analysis.
The mean $( \pm$ SD) age of participants was $37.84 \pm$ 12.41 years ranged from 18 to 77 years old, and $54.4 \%$ were females. Out of 318 participants, $46.9 \%$ were in the age group 30 to 49 years old, $67.4 \%$ were married and $61 \%$ were urban dwellers. Almost half of study participants had a habit of drinking alcohol, and $31.1 \%$ were actively infected with $H$. pylori. Sociodemographic and life style factors of study participants are described in Table 1.

\section{Dyspepsia and its associated factors}

Of 318 participants with complaints of GI symptoms, according to Rome III criteria, $63.5 \%$ had at least one self-reported functional GI symptom with the prevalence of UD being $48.4 \%$. Commonly reported upper GI symptoms were epigastric pain or burning, PPF, complain of ES and belching (Table 2).

Chi-square test showed that $H$. pylori infection was significantly associated with UD $\left(\chi^{2}=21.33, p<0.001\right)$ as were habit of taking aspirin and/or NSAIDs $\left(\mathrm{x}^{2}=\right.$ 30.27, $\mathrm{p}<0.001)$, consumption of tea $(\mathrm{x} 2=18.23, \mathrm{p}<$ $0.001)$ and raw fruit and/or vegetables $\left(x^{2}=8.71, p=\right.$

Table 1 Socio-demographic and lifestyle characteristics of functional gastrointestinal symptomatic adult patients in Dessie Referral Hospital, Northeastern Ethiopia, $2015(n=318)$

\begin{tabular}{|c|c|c|c|c|c|c|c|}
\hline Variable & & Freq & $\%$ & Variables & & Freq & $\%$ \\
\hline \multirow[t]{2}{*}{ Age (year) mean $\pm S D$} & $37.84 \pm 12.41$ & & & Eating spicy food & Yes & 269 & 84.6 \\
\hline & & & & & No & 49 & 15.4 \\
\hline \multirow[t]{3}{*}{ Age group } & $<30$ years & 105 & 33.01 & & & & \\
\hline & 30 to 49 years & 149 & 46.9 & Tea consumption & Never & 106 & 33.3 \\
\hline & $\geq 50$ years & 64 & 20.12 & & One cup/day & 96 & 30.2 \\
\hline \multirow[t]{2}{*}{ Sex } & Male & 145 & 45.6 & & >one cup/day & 116 & 36.5 \\
\hline & Female & 173 & 54.4 & Coffee consumption & Never & 114 & 35.8 \\
\hline \multirow[t]{3}{*}{ Marital status } & Married & 214 & 67.4 & & One cup/day & 53 & 16.7 \\
\hline & Single & 63 & 19.8 & & >one cup/day & 151 & 47.5 \\
\hline & Divorced/widowed & 41 & 12.9 & Raw fruits and/or Vegetable consumption & Never & 78 & 24.5 \\
\hline \multirow[t]{3}{*}{ Residence } & Rural & 73 & 23 & & at least once/day & 53 & 16.7 \\
\hline & Urban & 194 & 61 & & at least once/week & 187 & 58.8 \\
\hline & Suburban & 51 & 16 & Alcohol drinking & Yes & 156 & 49.1 \\
\hline \multirow[t]{6}{*}{ Occupation } & Gov,t & 108 & 34 & & No & 162 & 50.9 \\
\hline & Student & 29 & 9.1 & Recent drug consumption & Never & 187 & 58.8 \\
\hline & Farmer & 66 & 20.8 & & Aspirin/NSAIDs & 87 & 27.4 \\
\hline & Merchant & 51 & 16.0 & & Other drugs & 44 & 13.8 \\
\hline & Housewife & 51 & 16.0 & Blood group & Group A & 82 & 25.8 \\
\hline & Others & 13 & 4.1 & & Group B & 89 & 28.0 \\
\hline \multirow[t]{4}{*}{ Education } & No legal education & 50 & 15.7 & & Group AB & 21 & 6.6 \\
\hline & Grade 1-8 & 74 & 23.3 & & Group O & 126 & 39.6 \\
\hline & Grade 9-12 & 72 & 22.6 & H. pylori infection & Yes & 99 & 31.1 \\
\hline & College and above & 122 & 38.4 & & No & 219 & 68.9 \\
\hline
\end{tabular}


Table 2 Frequency and distribution of self-reported functional gastrointestinal symptoms in study population using Rome III criteria, Dessie Referral Hospital, Northeastern Ethiopia, 2015( $n=318)$

\begin{tabular}{|c|c|c|c|c|c|c|c|c|}
\hline \multicolumn{5}{|c|}{ Functional gastrointestinal symptoms } & \multicolumn{4}{|c|}{ Functional gastrointestinal symptoms } \\
\hline & & & Freq & $\%$ & & & Freq & $\%$ \\
\hline \multirow{2}{*}{\multicolumn{2}{|c|}{ At least one symptom }} & Yes & 202 & 63.5 & $U D \& H B$ & Yes & 78 & 24.5 \\
\hline & & No & 116 & 36.5 & & No & 240 & 75.5 \\
\hline \multirow[t]{2}{*}{ UD } & & Yes & 154 & 48.4 & Belching & Yes & 80 & 25.2 \\
\hline & & No & 164 & 51.6 & & No & 238 & 74.8 \\
\hline \multirow[t]{8}{*}{ UD typical symptoms } & PPF & Yes & 83 & 26.1 & vomiting & Yes & 18 & 5.7 \\
\hline & & No & 235 & 73.9 & & No & 300 & 94.3 \\
\hline & ES & Yes & 72 & 22.6 & Nausea & Yes & 11 & 3.5 \\
\hline & & No & 246 & 77.4 & & No & 307 & 96.5 \\
\hline & Epigastric burning/pain & Yes & 134 & 42.1 & UD \& belching & Yes & 66 & 20.8 \\
\hline & & No & 184 & 57.9 & & No & 252 & 79.2 \\
\hline & PPF and ES & Yes & 62 & 19.5 & UD, HB \& belching & Yes & 43 & 13.5 \\
\hline & & No & 256 & 80.5 & & No & 275 & 86.5 \\
\hline
\end{tabular}

Key: UD = uninvestigated dyspepsia, PPF = postprandial fullness, ES = early satiation, $\mathrm{HB}=$ heart burn

0.01) (Table 4). However, no significant association observed between sex, age, residence, educational level, occupational and marital status (Table 3), ABO blood group, consumption of coffee and spicy foods, drinking of alcohol and UD (Table 4).

Table 3 The prevalence of uninvestigated dyspepsia in relation to demographic variables among study participants in Dessie Referral Hospital, Northeastern Ethiopia, $2015(n=318)$

\begin{tabular}{|c|c|c|c|c|c|}
\hline Variable & & Total (N) & UD n (\%) & $x^{2}$ & $p$-value \\
\hline \multirow[t]{2}{*}{ Sex } & Male & 145 & $67(46.2)$ & 0.53 & 0.468 \\
\hline & Female & 173 & $87(50.3)$ & & \\
\hline \multirow[t]{3}{*}{ Age } & $<30$ years & 105 & $47(44.8)$ & 0.96 & 0.618 \\
\hline & 30 to 49 years & 149 & $76(51.0)$ & & \\
\hline & $\geq 50$ years & 64 & $31(48.4)$ & & \\
\hline \multirow[t]{3}{*}{ Marital status } & Married & 214 & $99(46.3)$ & 3.00 & 0.223 \\
\hline & Single & 63 & $30(47.6)$ & & \\
\hline & Divorced/widowed & 41 & $25(61.0)$ & & \\
\hline \multirow[t]{3}{*}{ Residence } & Rural & 73 & $38(52.1)$ & 2.83 & 0.242 \\
\hline & Urban & 194 & $87(44.8)$ & & \\
\hline & Suburban & 51 & $29(56.9)$ & & \\
\hline \multirow[t]{6}{*}{ Occupation } & Gov,t & 108 & $48(44.4)$ & 9.96 & 0.076 \\
\hline & Student & 29 & $16(55.2)$ & & \\
\hline & Farmer & 66 & $38(57.6)$ & & \\
\hline & Merchant & 51 & 20(39.2) & & \\
\hline & Housewife & 51 & $29(56.9)$ & & \\
\hline & Others & 13 & $3(23.1)$ & & \\
\hline \multirow[t]{4}{*}{ Education } & No legal education & 50 & $25(50.0)$ & 0.62 & 0.893 \\
\hline & Grade 1-8 & 74 & $38(51.4)$ & & \\
\hline & Grade 9-12 & 72 & $35(48.6)$ & & \\
\hline & College and above & 122 & $56(45.9)$ & & \\
\hline
\end{tabular}

Exploring independent risk factors in a logistic regression model showed that $H$. pylori infection $[\mathrm{AOR}=4.33$, 95\% CI 2.41-7.76, $p<0.001]$ and consumption of aspirin and/or NSAIDs $[\mathrm{AOR}=5.29,95 \%$ CI 2.82-9.93, $\mathrm{p}<$ 0.001] were independent predictors of UD. However, consumption of raw fruit and/or vegetables at least once a week $[\mathrm{AOR}=0.48,95 \%$ CI $0.24-0.98, p=0.042]$ and tea consumption at least two cups a day $[\mathrm{AOR}=0.34$, 95\% CI $0.17-0.70, p=0.003$ ] showed a protective effect against UD. No association was distinguished between consumption of one cup of tea a day, marital status, ABO blood group, type of occupation and UD (Table 5).

\section{Correlation of $H$. pylori infection to self-reported dyspepsia symptoms}

Univariate analysis showed that $H$. pylori infection is significantly correlated with upper GI complaints such as PPF, ES, Epigastric burning/pain, nausea as well as their overlaps (Table 6).

Constructing a multivariate logistic regression model in which the H.pylori $(+) /(-)$ variable taken as the dependent variable, and upper GI symptoms which were found to be significantly correlated in the univariate analysis as independent variables showed that $H$. pylori infection rate were significantly correlated with ES [AOR $=2.68,95 \%$ CI 1.38-5.20], epigastric burning/pain [AOR $=1.92,95 \%$ CI 1.07-3.43], belching $[\mathrm{AOR}=4.7,95 \% \mathrm{CI}$ $1.54-14.40]$ and nausea $[\mathrm{AOR}=3.91,95 \% \mathrm{CI} 1.03-14.87$ ] (Table 6).

\section{Discussion}

In the present study, $63.5 \%$ of study participants had at least one GI symptom. Park et al. in Korea reported that 
Table 4 The prevalence of uninvestigated dyspepsia in relation to lifestyle and other factors of study participants in Dessie Referral Hospital, Northeastern Ethiopia, $2015(n=318)$

\begin{tabular}{|c|c|c|c|c|c|}
\hline Variables & & Total & $U D=n / \%$ & $x^{2}$ & P-value \\
\hline \multirow[t]{2}{*}{ Eating spicy food } & Yes & 269 & 132(49.1) & 0.29 & 0.591 \\
\hline & No & 49 & $22(44.9)$ & & \\
\hline \multirow[t]{3}{*}{ Tea consumption } & Never & 106 & $59(55.7)$ & 18.23 & $<0.000$ \\
\hline & One cup/day & 96 & $57(59.4)$ & & \\
\hline & >one cup/day & 116 & $38(32.8)$ & & \\
\hline \multirow[t]{3}{*}{ Coffee consumption } & Never & 114 & $54(47.4)$ & 0.19 & 0.911 \\
\hline & One cup/day & 53 & $27(50.9)$ & & \\
\hline & >one cup/day & 151 & $73(48.3)$ & & \\
\hline \multirow[t]{3}{*}{ Raw fruits and/or Vegetables consumption } & Never & 78 & $49(62.8)$ & 8.71 & 0.013 \\
\hline & Eat at least once/day & 53 & $22(41.5)$ & & \\
\hline & Eat at least once/week & 187 & $83(44.4)$ & & \\
\hline \multirow[t]{2}{*}{ Alcohol drinking } & Yes & 156 & $79(50.6)$ & 0.60 & 0.438 \\
\hline & No & 162 & $75(46.3)$ & & \\
\hline \multirow[t]{3}{*}{ Recent drug consumption } & Never & 187 & $67(35.8)$ & 30.27 & $<0.000$ \\
\hline & Aspirin/NSAIDs & 87 & $61(70.1)$ & & \\
\hline & Other drugs & 44 & $26(59.1)$ & & \\
\hline \multirow[t]{4}{*}{ Blood group } & Group A & 82 & $37(45.1)$ & 6.51 & 0.089 \\
\hline & Group B & 89 & $35(39.3)$ & & \\
\hline & Group AB & 21 & $12(57.1)$ & & \\
\hline & Group $O$ & 126 & $70(55.6)$ & & \\
\hline \multirow[t]{2}{*}{ H. pylori infection } & Yes & 99 & $67(67.7)$ & 21.33 & $<0.000$ \\
\hline & No & 219 & 87(39.7) & & \\
\hline
\end{tabular}

among new consecutive patients presented with chronic GI symptoms $73.9 \%$ had upper gastroduodenal symptoms [4]. This variation could be due to differences in socioeconomic and life style factors contributing for gastrointestinal disorders.

In our study, using Rome III diagnostic criteria, the prevalence of UD was $48.8 \%$ which is higher than study conducted in African countries such as Nigeria (37.5\%) [29] and Uganda (38.9\%) [30], but the diagnostic criteria (Rome II) are quite different from current study. Our result is also higher than study conducted in Asian countries such as Korea (13.4\%) [11], China (5.67\%) [31], Taiwan (32.4\%) [32], west part of Iran (41.2\%) [12]; and European countries like UK (38\%) [22] and Italy (15.1\%), where Rome II criteria is employed as main diagnostic criteria [20]. However, our result is lower than another study conducted in Nigeria with $69.1 \%$ prevalence of UD among upper gastrointestinal symptomatic patients [33].

The observed variable proportion of UD may be partly explained with variation in geographical location, use of variable definitions and criteria for diagnosis of dyspepsia, study design and population. For instance, some studies employed Rome III criteria for diagnosis of dyspepsia [31-33] which is comparable to our work, but the design of most mentioned studies, whether employed Rome II or III criteria, [12, 20, 22, 29-32] are population based surveys involving asymptomatic patients. However, the high proportion of UD in our and Nigerian [33] study is due to being hospital based study where clinically suspected patients involved. Moreover, in our and other African studies [29, 30,33] the prevalence of UD is higher as compared to studies conducted in Asia. This might be delayed presentation of patients to health care provider in African countries and the result of variation in dietary factors, socio-cultural and psychological issues, rate of gastrointestinal infection mainly caused by $H$. pylori. As a result eastern life styles may be a factor related to the lower prevalence dyspepsia.

The most common symptoms associated with UD was found to be epigastric pain/burning (42.1\%), PPF (26.1\%), ES (22.6\%) and belching (25.2\%) (Table 2). Similarly, among Ugandan patients presenting with upper GI symptoms the most common presenting complaint was epigastric pain (51.6\%) [34]. Our result is also in line with study in Iran as epigastric pain or burning (58.3\%) being dominant complaint of dyspeptic patients followed by PPF (37.3\%) and ES (18.6\%) [35]. Belching disorders (30.7\%) was the dominant symptoms next to FD (46\%) 
Table 5 Regression analysis of different factors associated with uninvestigated dyspepsia of study participants in Dessie Referral Hospital, Northeastern Ethiopia, $2015(n=318)$

\begin{tabular}{|c|c|c|c|c|c|c|}
\hline Variable & & Total & $\mathrm{UD}=\mathrm{n}(\%)$ & COR $(95 \% \mathrm{Cl})$ & AOR(95\%Cl) & $p$-value \\
\hline \multirow[t]{3}{*}{ Marital status } & Married & 214 & $99(46.3)$ & ref & & \\
\hline & Single & 63 & $30(47.6)$ & $1.06(0.60-1.85)$ & - & - \\
\hline & Divorced/widowed & 41 & $25(61.0)$ & 1.82(0.92-3.59) & - & - \\
\hline \multirow[t]{3}{*}{ Residence } & Rural & 73 & $38(52.1)$ & ref & ref & \\
\hline & Urban & 194 & $87(44.8)$ & $0.75(0.44-1.28)$ & $2.32(0.73-7.34)$ & 0.152 \\
\hline & Suburban & 51 & $29(56.9)$ & $1.21(0.59-2.49)$ & 4.71(1.44-15.39) & $0.010^{*}$ \\
\hline \multirow[t]{6}{*}{ Occupation } & Gov,t & 108 & $48(44.4)$ & ref & & \\
\hline & Student & 29 & $16(55.2)$ & $1.54(0.68-3.51)$ & - & - \\
\hline & Farmer & 66 & $38(57.6)$ & $1.70(0.91-3.15)$ & - & - \\
\hline & Merchant & 51 & 20(39.2) & $0.81(0.41-1.59)$ & - & - \\
\hline & Housewife & 51 & $29(56.9)$ & $1.65(0.84-3.23)$ & - & - \\
\hline & Others & 13 & $3(23.1)$ & $0.38(0.10-1.44)$ & - & - \\
\hline \multirow[t]{3}{*}{ Tea consumption } & Never & 106 & $59(55.7)$ & ref & ref & \\
\hline & One cup/day & 96 & $57(59.4)$ & $1.16(0.67-2.04)$ & $0.99(0.47-2.07)$ & 0.975 \\
\hline & >one cup/day & 116 & $38(32.8)$ & $0.39(0.23-0.67)$ & $0.34(0.17-0.70)$ & $0.003^{*}$ \\
\hline \multirow[t]{3}{*}{ Raw fruit/ Vegetable consumption } & Never & 78 & $49(62.8)$ & ref & ref & \\
\hline & Eat once/day & 53 & $22(41.5)$ & $0.42(0.21-0.86)$ & $0.31(0.13-0.77)$ & $0.011^{*}$ \\
\hline & Eat once/week & 187 & $83(44.4)$ & $0.47(0.28-0.81)$ & $0.48(0.24-0.98)$ & $0.042^{*}$ \\
\hline \multirow[t]{3}{*}{ Recent drug consumption } & Never & 187 & $67(35.8)$ & ref & ref & \\
\hline & Aspirin/NSAID & 87 & $61(70.1)$ & $4.20(2.43-7.27)$ & $5.29(2.82-9.93)$ & $<0.001^{*}$ \\
\hline & Other drugs & 44 & $26 / 59.1$ & $2.59(1.32-5.06)$ & $3.12(1.46-6.69)$ & $0.003^{*}$ \\
\hline \multirow[t]{4}{*}{ Blood group } & Group A & 82 & $37 / 45.1$ & ref & & \\
\hline & Group B & 89 & $35 / 39.3$ & $0.79(0.43-1.45)$ & - & - \\
\hline & Group AB & 21 & $12 / 57.1$ & $1.62(0.62-4.27)$ & - & - \\
\hline & Group $O$ & 126 & $70 / 55.6$ & $1.52(0.87-2.66)$ & - & - \\
\hline \multirow[t]{2}{*}{ H. pylori infection } & No & 219 & $87 / 39.7$ & ref & ref & \\
\hline & Yes & 99 & $67 / 67.7$ & $3.18(1.93-5.24)$ & $4.33(2.41-7.76)$ & $<0.001^{*}$ \\
\hline
\end{tabular}

among functional gastroduodenal disorders in Korean patients with chronic GI complaints [4].

Correlation of $H$. pylori infection with each upper GI symptoms is shown in Table 6. There was no correlation between PPF, combination of UD and heart burn, and vomiting with $H$. pylori infection. However, significant correlation was found between ES, epigastric pain/burning, belching, and nausea with $H$. pylori infection. The proportion of belching is more among $H$. pylori infected patients as compared to $H$. pylori free patients. i.e., presentation of belching is 4.7 times more likely to be associated with H.pylori infection as compared to $H$. pylori free patients. Our result is in agreement to report of Shokrzadeh et al. in Iran where the prevalence of belching was significantly higher among $H$. pylori infected patients with no correlation of vomiting [36]. This significant likelihood association $H$. pylori infection to belching could be explained as $H$. pylori is known to produces urease which helps to metabolizes urea into ammonia and carbon dioxide resulting in belching and bloating. However, our result is found contrary to his report where no difference was observed in the prevalence of epigastric abdominal pain, nausea, and ES between $H$. pylori-positive and $H$. pylori-negative patients [36]. This may be due to variation in laboratory tests for diagnosis of $H$. pylori infection (stool antigen detection in our case where as histological examination in Iranian study), population variation and lifestyle factors.

The association of $H$. pylori infection with UD has been reported with inconsistent findings in several studies. In our study, however, $H$. pylori infection was found to be significantly associated with UD (AOR $=4.33,95 \%$ CI $2.41-7.76, p<0.001)$ which is similar to study conducted in Taiwan [32], Kenya [37] and Ethiopia [23]. A large population based study in Denmark also showed that $H$. pylori infection is a significant risk factor for 
Table 6 Regression analysis on comparison of self-reported upper gastrointestinal symptoms between H.pylori $(+)(n=99)$ and H.pylori $(-)(n=219)$ patients, Dessie Referral Hospital, 2015

\begin{tabular}{|c|c|c|c|c|c|c|c|}
\hline \multicolumn{2}{|c|}{ Self-reported Upper gastrointestinal symptoms } & \multirow{2}{*}{$\begin{array}{l}\mathrm{HP}(+)=\mathrm{n}(\%) \\
41(41.5)\end{array}$} & \multirow{2}{*}{$\begin{array}{l}\mathrm{HP}(-)=\mathrm{n}(\%) \\
42(19.2)\end{array}$} & \multirow{2}{*}{$\frac{\operatorname{COR}(\mathrm{Cl})}{2.98(1.76-5.02)}$} & \multirow{2}{*}{$\frac{p \text {-value }}{<0.001}$} & \multirow{2}{*}{$\frac{\mathrm{AOR}(\mathrm{Cl})}{-}$} & \multirow{2}{*}{$\frac{p \text {-value }}{-}$} \\
\hline PPF & Yes & & & & & & \\
\hline & No & $58(48.5)$ & 177(80.8) & ref & & & \\
\hline \multirow[t]{2}{*}{ ES } & Yes & 39(39.4) & $33(15.1)$ & $3.66(2.12-6.33)$ & $<0.001$ & $2.68(1.38-5.20)$ & $0.004^{*}$ \\
\hline & No & $60(60.6)$ & 186(84.9) & ref & & ref & \\
\hline \multirow[t]{2}{*}{ Epigastric burning/pain } & Yes & $58(58.6)$ & $76(34.7)$ & $2.66(1.64-4.33)$ & $<0.001$ & $1.92(1.07-3.43)$ & $0.028^{*}$ \\
\hline & No & $41(41.4)$ & 143(65.3) & ref & & ref & \\
\hline \multirow[t]{2}{*}{ PPF \& ES } & Yes & $34(34.3)$ & $28(12.8)$ & $3.57(2.01-6.33)$ & $<0.001$ & - & - \\
\hline & No & $65(65.7)$ & 191(87.2) & ref & & & \\
\hline \multirow[t]{2}{*}{$U D \& H B$} & Yes & $40(40.4)$ & $38(17.4)$ & $3.23(1.90-5.50)$ & $<0.001$ & - & - \\
\hline & No & 59(59.6) & 181(82.6) & ref & & & \\
\hline \multirow[t]{2}{*}{ Belching } & Yes & $40(40.4)$ & $40(18.3)$ & $3.47(1.05-12.57)$ & 0.050 & $4.70(1.54-14.4)$ & $0.007^{*}$ \\
\hline & No & 59(59.6) & 179(81.7) & ref & & ref & \\
\hline \multirow[t]{2}{*}{ vomiting } & Yes & $9(9.1)$ & $9(4.1)$ & $2.33(0.90-6.07)$ & 0.082 & - & - \\
\hline & No & 90(90.9) & 210(95.9) & ref & & & \\
\hline \multirow[t]{2}{*}{ Nausea } & Yes & $7(7.1)$ & $4(1.8)$ & $4.09(1.17-14.31)$ & 0.028 & $3.91(1.03-14.87)$ & $0.045^{*}$ \\
\hline & No & $92(92.9)$ & 215(98.2) & ref & & ref & \\
\hline \multirow[t]{2}{*}{ UD \& bleaching } & Yes & 33(33.3) & $33(15.1)$ & $2.82(1.61-4.93)$ & $<0.001$ & $0.28(0.06-1.01)$ & 0.051 \\
\hline & No & $66(66.7)$ & 186(84.9) & ref & & ref & \\
\hline \multirow[t]{2}{*}{ UD, HB \& bleaching } & Yes & $25(25.3)$ & $18(8.2)$ & $3.77(1.95-7.31)$ & $<0.001$ & - & - \\
\hline & No & $74(74.7)$ & 201(91.8) & ref & & & \\
\hline
\end{tabular}

Key: $\mathrm{PPF}=$ postprandial fullness, $\mathrm{ES}=$ early satiation, $\mathrm{AOR}=$ adjusted oddis ratio, $\mathrm{COR}=$ crude oddis ratio, $\mathrm{HP}=\mathrm{H} . \mathrm{pylori}, \mathrm{HB}=$ heart burn, $\mathrm{Cl}=\mathrm{confidence}$ interval, $\mathrm{UD}=$ uninvestigated dyspepsia

dyspepsia although of less importance than NSAIDs use, unemployment and heavy smoking [38]. However, other authors indicated no association between $H$. pylori infection and dyspepsia $[18-20,39]$ as most $H$. pylori infected individuals didn't show dyspepsia [40-43].

Even though some surveys have indicated association of dyspepsia with alcohol consumption [44, 45], our result showed no significant association between coffee and alcohol consumption with UD which is in agreement with studies conducted elsewhere in the world reporting no association with dyspepsia $[17,19,20,39,46,47]$. This discordance could be due to difference in type and amount of alcohol consumed as well as sociocultural practices of study population. Moreover, in our study in addition to small sample size we didn't determine the amount and type of consumed alcohol, as well as the type of coffee consumed so that further population-based study is needed to elucidate their association with dyspepsia.

Our result also showed that NSAIDs use is statistically associated with UD (AOR $=5.29$, 95\% CI 2.829.93, $p<0.001)$ which is in agreement with British and American populations based studies where NSAIDs use have been identified as an important independent risk factor for UD [22, 32, 46]. However, population based study in Italy and Sweden showed no association between use of NSAIDs/aspirin or corticosteroids and UD [20,39]. Sex and age matched case control study conducted in Nigeria showed that NSAIDs user for a minimum of one week prior to 30 days before enrolment to the study did not show any association with UD [19].

Our study also showed that consumption of two or more cup of tea a day $(\mathrm{AOR}=0.34,95 \% \mathrm{CI} 0.17-0.70$, $p=0.003)$ and consumption of raw fruits and/or vegetables at least once a day ( $\mathrm{AOR}=0.31,95 \%$ CI 0.13 $0.77, p=0.011$ ) was protective against UD which is in agreement with reports of Khademolhosseini et al. in Iran, where inverse relationship was observed between dyspepsia and fruits as well as vegetables consumption [47]. However, Seyedmirzaei et al. in Iran, by controlling possible confounding factors, showed no protective effect of high fruit and vegetable consumption, and current tea-coffee consumption [35]. Hospital-based study in Taiwan also showed no significant association between consumption of tea, vegetable and UD, but consumption of coffee was protective against UD [32]. Contrary to above findings, Solomon et al. in Nigeria indicated significant association of high amount of tea consumption and UD [19]. This may depend on the type of tea, fruit 
and vegetables as well as type of biological molecules that can be found within it, which is not investigated in our study and others too. Thus, future well designed study is warranted to assess whether different kinds of tea as well as fruit and vegetables have different biological effects in the pathogenesis of dyspepsia.

The strength of our study is that we have included new patients by using randomized recruitment strategy to represent all patients with symptoms of GI disorders. However, the cross-sectional nature of this study has a limitation to show cause and effect associations between UD and associated factors, and the result cannot be representative of the general population. This study is a hospital based study involving subjects with symptoms who have had many underline disease conditions as a confounding factors that could not fully controlled so that it might have impact on the statistical correlations between dyspepsia and other variables of interest.

\section{Conclusions}

In conclusion, this is the first hospital-based study in Ethiopia for assessing UD among patients with FGIDs using Rome III criteria. The prevalence of UD in the study population was $48.4 \%$, with epigastric pain/burning being the most prevalent symptom (42.1\%). The observed high proportion of UD alerts health care providers and program planners about the disease, and suggesting a critical management issue of dyspepsia in the country. H. pylori infection is significantly associated with UD and habit of aspirin/NSAIDs consumption. However, consumption of raw fruit and/or vegetable at least once a day and more than one cup of tea a day showed inverse association with UD which needs further well designed study to ascertain the observed association. Upper GI symptoms such as early satiation, epigastric burning/pain, belching, and nausea showed strong likelihood association with $H$. pylori infection.

\section{Abbreviations}

ES: early satiation; FD: functional dyspepsia; FGIDs: functional gastrointestinal disorders; Gl: gastrointestinal; NSAIDS: nonsteroidal anti-inflammatory drugs; PPF: post prandial fullness; UD: uninvestigated dyspepsia

\section{Acknowledgements}

We would like to express our special thanks to the staff of Dessie Referral Hospital for technical support in this study. Moreover, we would like to thank the study participants.

\section{Funding}

This study was supported by Wollo University. The funders had no role in study design, data collection and analysis, decision to publish, or preparation of the manuscript.

\section{Availability of data and materials}

The authors confirm that all data underlying the findings are available at our hands. The corresponding author is responsible to be contacted and justify any question regarding to the result. All relevant data are within the manuscript.

\section{Authors' contributions}

ASY: design of the study; acquisition of data, data management, analysis, interpretation of data and manuscript preparation. ZM: contributed to the design of the study, manuscript preparation and study supervision. WD: contributed to the design of the study, manuscript preparation and study supervision. All authors have read and approved the final manuscript.

\section{Ethics approval and consent to participate}

The study was commenced after ethically approved by the research ethics committee of Wollo University. Permission to conduct the study was also obtained from the hospital administration. Written informed consent was obtained from each study participant and the results were kept confidential. Any result that was necessary for the patient was communicated with the physician for appropriate management.

\section{Consent for publication}

Not applicable.

\section{Competing interests}

The authors declare that they have no competing interests.

\section{Publisher's Note}

Springer Nature remains neutral with regard to jurisdictional claims in published maps and institutional affiliations.

\section{Author details}

'Department of Medical Laboratory Sciences, College of Medicine and Health Sciences, Wollo University, Po. Box 1145, Dessie, Ethiopia.

${ }^{2}$ Department of Medical Laboratory Sciences, College of Health Sciences, School of Allied Health Sciences, Addis Ababa University, Addis Ababa, Ethiopia. ${ }^{3}$ Department of Medical Laboratory Sciences, College of Medicine and Health Sciences, Wollo University, Dessie, Ethiopia.

Received: 20 May 2017 Accepted: 1 December 2017

Published online: 18 January 2018

\section{References}

1. Talley NJ, Zinsmeister AR, Schleck CD, Melton L. Dyspepsia and dyspepsia subgroups: a population-based study. Gastroenterology. 1992;102:1259-68.

2. Nyrop KA, Palsson OS, Levy RL, Von Korff M, Feld AD, Turner MJ, Whitehead WE. Costs of health care for irritable bowel syndrome, chronic constipation, functional diarrhoea and functional abdominal pain. Aliment Pharmacol Ther. 2007;26(2):237-48.

3. Drossman DA, Corazziari E, Delvaux M, Spiller RC, Talley NJ, Thompson WG, et al. In: Drossman DA, Corazziari E, Delvaux M, Spiller RC, Talley NJ, Thompson WG, Whitehead WE, editors. The functional gastrointestinal disorders. 3rd edn. Virginia: Degnon associates, Inc., McLean; 2006. p. 963-90.

4. Park JM, Choi MG, Cho YK, Lee IS, Kim JI, Kim SW, Chung IS. Functional gastrointestinal disorders diagnosed by Rome III questionnaire in Korea. J Neurogastroenterol Motil. 2011;17(3):279-86.

5. Wallander MA, Johansson S, Ruigomez A, Garcia Rodriguez LA, Jognes R. Dyspepsia in general practice: incidence, risk factors, comorbidity and mortality. Fam Pract. 2007;24:403-11.

6. Tack J, Talley NJ, Camilleri M, Holtmann G, Hu P, Malagelada J-R, Stanghellini V. Functional gastroduodenal disorders. Gastroenterology. 2006;130:1466-79.

7. Tepeš B. Subgroups of dyspepsia. In: Duvnjak M, editor. Dyspepsia in clinical practice. Springer; 2011. p. 9-18.

8. Boyce PM, Talley NJ, Burke C, Koloski NA. Epidemiology of the functional gastrointestinal disorders diagnosed according to Rome II criteria: an Australian population-based study. Intern Med J. 2006;36:28-36.

9. Drossman DA1, Li Z, Andruzzi E, Temple RD, Talley NJ, Thompson WG, Whitehead WE, Janssens J, Funch-Jensen P, Corazziari E,. U.S. householder survey of functional gastrointestinal disorders. Prevalence, sociodemography, and health impact. Dig DisSci.1993;38: 1569-80.

10. Hasan M. Dyspepsia in primary care practice in Bangladesh. Bangladesh Med I .2013; 42 (2):63-69. A review article.

11. Ghoshal UC, Singh R, Chang FY, Hou X, Wong BC, Kachintorn U. Epidemiology of uninvestigated and functional dyspepsia in Asia: facts and fiction. J Neurogastroenterol Motil. 2011;17(3):235-44. doi: https://doi.org/10. 5056/jnm.2011.17.3.235. 
12. Yazdanpanah K, Moghimi N, Yousefinejad V, Ghaderi E, Azizi A, Nazem SF. Dyspepsia prevalence in general population aged over 20 in the west part of Iran. J Pak Med Assoc. 2012;62(7):672-6.

13. Ford AC, Marwaha A, Sood R, Moayyedi P. Global prevalence of, and risk factors for, uninvestigated dyspepsia: a meta-analysis. Gut. 2015;64:1049-57.

14. Talley NJ, Ford AC. Functional dyspepsia. N Engl J Med. 2015;373:1853-63.

15. Piessevaux H, De Winter B, Louis E, Muls V, De Looze D, Pelckmans $P$, Deltenre $M$, Urbain D, Tack J. Dyspeptic symptoms in the general population: a factor and cluster analysis of symptom groupings. Neurogastroenterol Motil. 2009;21(4):378-88.

16. Tack J, Bisschops R, Sarnelli G. Pathophysiology and treatment of functional dyspepsia. Gastroenterology. 2004;127:1239-55.

17. Mahadeva S, Goh KL. Epidemiology of functional dyspepsia: a global perspective. World J Gastroenterol. 2006;12(17):2661-6.

18. Rejchrt S, Koupil I, Kopa 'čva' M, Vor, 'šek V, Seifert B, Pozler O. Prevalence and sociodemographic determinants of uninvestigated dyspepsia in the Czech Republic. Eur J Gastroenterol Hepatol 2008; 20: 898-905.

19. Solomon OA, Ajayi AO. Risk factors for un-investigated dyspepsia among primary care patients in northern Nigeria. African health Science. 2013;13(4): 1007-11.

20. Zagari RM, Law GR, Fuccio L, Cennamo V, Gilthorpe MS, Forman D, Bazzoli F. Epidemiology of functional dyspepsia and subgroups in the Italian general population: an endoscopic study. Gastroenterology. 2010;138(4): 1302-11.

21. Tesfahun T, Yohannes M, Kassu D, Daniel A. Seroprevalence of helicobacter pylori infection in and its relationship with $\mathrm{ABO}$ blood groups. Ethiop.J. Health Dev .2005; 19(1):55-59.

22. Moayyedi P, Forman D, Braunholtz D, Feltbower R, Crocombe W, Liptrott M, Axon A. The proportion of upper gastrointestinal symptoms in the community associated with helicobacter pylori, lifestyle factors, and nonsteroidal anti-inflammatory drugs. Leeds HELP study group. The Am J Gastroenterol. 2000;95(6):1448-55.

23. Gizachew T, Abebe H, Kassu D, Samuel E, Abate B. Association of dyspepsia symptoms and Helicobacter pylori infections in private higher clinic, Addis Ababa, Ethiopia. Ethiop Med J. 2011; 49 (2). Abstract.

24. Moges F, Kassu A, Mengistu G, Adugna S, Andualem B, Nishikawa T, Ota F. Seroprevalence in dyspeptic patients and its relationship with HIV infection, ABO blood group and life style in a university hospital, north west Ethiopia. World J Gastroenterol. 2006;12(12):1957-61.

25. Wubejig A, Mulugeta K, Bayeh A. Prevalence and risk factors of $\mathrm{H}$. Pylori from dyspeptic patients in Northwest Ethiopia: a hospital based crosssectional study. Asian Pac J Cancer Prev. 2014;15(11):4459-63.

26. Asrat D, Nilsson I, Mengistu Y, Ashenafi S, Ayenew K, Al-Soud WA, Wadström T, Kassa E. Prevalence of helicobacter pylori infection among adult dyspeptic patients in Ethiopia. Trop Med Parasitol. 2004;98(2):181-9.

27. Rome Foundation, "Rome III: A self-reported integrated questionnaire to diagnose adults for one or more functional gastrointestinal disorders, including alarm symptoms/red flags," https://theromefoundation.org/ products/copyright-and-licensing/.

28. Demiray E, Yilmaz O, Sarkis C, Soyturk M, Simsek I. Comparison of invasive methods and two different stool antigen tests for diagnosis of H. Pylori infection in patients with gastric bleeding. World J Gastroenterol. 2006; 12(26):4206-10.

29. Ogunmodede JA, Bojuwoye MO, Olokoba AB, Bolarinwa OA, Kolo PM. Selfreported symptoms of uninvestigated dyspepsia among university staff in Ilorin, Nigeria. Res. J. of Health Sci. 2016;4(4):296-303.

30. Bitwayiki R, Orikiiriza JT, Kateera F, Bihizimana P, Karenzi B, Kyamanywa P, Walker TD. Dyspepsia prevalence and impact on quality of life among Rwandan healthcare workers: a cross-sectional survey. S Afr Med J. 2015; 105(12):1064-9.

31. Li M, Lu B, Chu L, Zhou H, Chen M-Y. Prevalence and characteristic of dyspepsia among college students in Zhejiang province. World $\mathrm{j}$ gastronology. 2014;20(13):3649-54.

32. Lee J-Y, Hsu Y-C, Chen M-J, Tseng P-H, Chang C-Y, Yang T-H, Chang W-H, JY W, Wang H-P, Luo J-C, Lin J-T, Shun C-T, Distinct WM-S. Aetiopathogenesis in subgroups of functional dyspepsia according to the Rome III criteria. Gut. 2015;64:1517-28. https://doi.org/10.1136/gutjnl-2014308114

33. Nwokediuko SC, ljoma U, Obienu O. Functional Dyspepsia: Subtypes, Risk Factors, and Overlap with Irritable Bowel Syndrome in a Population of
African Patients. Gastroenterology Research and Practice, Article ID. 2012: 562393, 5 pages. doi: https://doi.org/10.1155/2012/562393.

34. Obayo S, Muzoora C, Ocama P, Cooney MM, Wilson T, Probert CS. Upper gastrointestinal diseases in patients for endoscopy in south-western Uganda. Afri Health Sci. 2015;15(3):959-66. https://doi.org/10.4314/ahs.v15i3.33.

35. Seyedmirzaei S M, Haghdoost AA, Afshari M; Dehghani A. Prevalence of Dyspepsia and its Associated Factors Among the Adult Population in Southeast of Iran in 2010. Iran Red Crescent Med J. 2014; 16(11): e14757. doi: https://doi.org/10.5812/ircmj.14757.

36. Shokrzadeh L, Baghaei K, Yamaoka Y, Shiota S, Mirsattari D, Porhoseingholi A, Zali MR. Prevalence of helicobacter pylori infection in dyspeptic patients in Iran. Gastroenterology Insights. 2012;4:e8. doi: https:/doi.org/10.4081/gi.2012.e8.

37. Shmuely H, Samson O, Douglas J, Abuksis G, Yahav J, Fraser G, Pitlik S, Niv Y yspepsia symptoms and Helicobacter pylori infection, Nakuru, Kenya. Emerging Infectious Diseases. 2003:9(9):1103-7.

38. Wildner-christensen M, Hansen J M \& Schaffalitzky de muckadell O B. Risk factors for dyspepsia in a general population: non-steroidal anti-inflammatory drugs, cigarette smoking and unemployment are more important than helicobacter pylori infection. Scand J Gastroenterol 2006; 41: 149-154.

39. Aro P, Talley NJ, Ronkainen J, Storskrubb T, Vieth M, Johansson SE, Bolling-sternevald E, Agréus L, Anxiety I. Associated with uninvestigated and functional dyspepsia(Rome III criteria) in a Swedish populationbased study. Gastroenterology. 2009;137:94-100.

40. Suzuki H, Matsuzaki J, Hibi T. What Is the Difference between Helicobacter pylori Associated Dyspepsia and Functional Dyspepsia?. J Neurogastroenterol Motil. 2011; 17(2):124-30. Review article.

41. Mohammad MA, Altayar M, Toboli AB, Bakk A. Characteristics of helicobacter pylori infection in libyan healthy peoples in two teaching hospitals in benghazi. Medical Journal of Islamic World Academy of Sciences. 2011;19(1):27-32.

42. Aguemon BD, Struelens MJ, Massougbodji A, Ouendo EM. Prevalence and risk factors for helicobacter pylori infection in urban and rural Beninese populations. Clin Microbiol Infect. 2005:11:611-7.

43. Khan MA, Ghazi HO. Helicobacter pylori infection in asymptomatic subjects in Makkah Saudi Arabia. JPMA. 2007:57(3):114-7.

44. Shah SS, Bhatia SJ, Mistry FP. Epidemiology of dyspepsia in the general population in Mumbai. Indian J Gastroenterol. 2001:20:103-6.

45. Haque M, Wyeth JW, Stace NH, Talley NJ. Prevalence, severity and associated features of gastro-oesophageal reflux and dyspepsia: a population-based study. N Z Med J. 2000;113:178-81.

46. Shaib Y, El-Serag HB. The prevalence and risk factors of functional dyspepsia in a multiethnic population in the United States. Am J Gastroenterol. 2004; 99:2210-6.

47. Khademolhosseini F, Mehrabani D, Zare N, Salehi M, Heydari ST, Beheshti M, Saberi-Firoozi M. Prevalence of dyspepsia and its correlation with demographic factors and lifestyle in shiraz, southern Iran. Middle East Journal of Digestive Diseases. 2010;2(1):24-30.

\section{Submit your next manuscript to BioMed Central and we will help you at every step:}

- We accept pre-submission inquiries

- Our selector tool helps you to find the most relevant journal

- We provide round the clock customer support

- Convenient online submission

- Thorough peer review

- Inclusion in PubMed and all major indexing services

- Maximum visibility for your research

Submit your manuscript at www.biomedcentral.com/submit
) Biomed Central 